\title{
Saros Körfezi’ndeki (Kuzey Ege Denizi, Türkiye) Kupes Balığının (Boops boops Linnaeus, 1758) Üreme Zamanı ve Ağırlık-Boy İlişsisinin Belirlenmesi
}

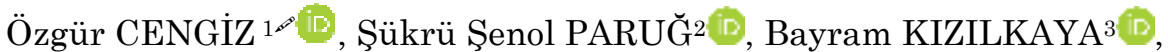 \\ ${ }^{1}$ Van Yüzüncü Yıl Üniversitesi, Su Ürünleri Fakültesi, Van, ${ }^{2}$ Kastamonu Üniversitesi, Su Ürünleri Fakültesi, Kastamonu, ${ }^{3}$ Çanakkale Onsekiz \\ Mart Üniversitesi, Deniz Bilimleri ve Teknolojisi Fakültesi, Çanakkale \\ ${ }^{1}$ https://orcid.org/0000-0003-1863-3482, ${ }^{2}$ https://orcid.org/0000-0002-7991-4651, ${ }^{3}$ https://orcid.org/0000-0002-3916-3734, \\ $凶$ : ozgurcengiz17@gmail.com
}

\begin{abstract}
ÖZET
$\mathrm{Bu}$ çalışma Ocak 2014-Aralık 2015 tarihleri arasında Saros Körfezi’nde yürütülmüştür. Türün üreme zamanı gonadların aylık ağırlık değişimleri dikkate alınarak GSI (Gonadosomatik indeks) = (Gonad Ağırlığı / Vücut ağırlığı - Gonad Ağırlığı) × 100 eşitliğinden, ağırlık-boy ilişkisi ise $\mathrm{W}=\mathrm{aL}^{\mathrm{b}}$ denklemi kullanılmak suretiyle elde edilmiştir. Üreme zamanının Mart ve Mayıs ayları arasında olduğu gözlemlenmiş̧tir. Dişi bireyler için ağırlık-boy ilişkisi $\mathrm{W}=$ $0.0085 \mathrm{TL}^{3.11}$, erkek bireyler için $\mathrm{W}=0.0095 \mathrm{TL}^{3.07}$ olarak hesaplanmiştır.
\end{abstract}

Araştırma Makalesi

Makale Tarihçesi

Geliş Tarihi : 23.01.2019

Kabul Tarihi : 14.03 .2019

\section{Anahtar Kelimeler}

Boops boops

Kupes

Üreme zamanı

Ağırlık-Boy İlişkisi

Saros Körfezi

\section{Weight-Length Relationship and Reproduction of Bogue (Boops boops Linnaeus, 1758) in Saros Bay (Northern Aegean Sea, Turkey)}

\begin{abstract}
This study was conducted between January 2014 and December 2015 in Saros Bay. The spawning period was estimated by monthly analyses, the changes of the gonad somatic index (GSI) using the equation: GSI $=($ Gonad Weight $/$ Total Weight - Gonad Weight $) \times 100$. The weight - length relationship was calculated using the equation $\mathrm{W}$ $=\mathrm{aL}$. It was observed that spawning period occurred between March and May. The weight-length relationship was calculated as $\mathrm{W}=$ $0.0085 \mathrm{TL}^{3.11}$ for females, $\mathrm{W}=0.0095 \mathrm{TL}^{3.07}$ for males.
\end{abstract}

\section{Research Article}

$\begin{array}{ll}\text { Article History } & \\ \text { Received } & : 23.01 .2019 \\ \text { Accepted } & : 14.03 .2019\end{array}$

Keywords
Boops boops
Bogue
Reproduction
Weight-Length Relationship
Saros Bay

To Cite : Cengiz Ö, Paruğ SS, Kızılkaya B, 2019. Saros Körfezi’ndeki (Kuzey Ege Denizi, Türkiye) Kupes Balığının (Boops boops Linnaeus, 1758) Üreme Zamanı ve Ağırlık-Boy İlişkisinin Belirlenmesi. KSÜ Tarım ve Doğa Derg 22(4): 577-582. DOI: 10.18016/ksutarimdoga.vi.516700

\section{GIRISŞ}

Kupes balığı (Boops boops Linnaeus, 1758) Akdeniz havzasının tüm kıyılarında dağılım gösteren, çeşitli dip yapısına sahip yerlerde yaşayan, semipelajik veya demersal bir türdür (Bauchot ve Hureau, 1986). Tüm denizlerimizde dağılım gösterdiği bilinen (Fricke ve ark., 2007) kupes balığı özellikle kış aylarında Yunanistan ve Ittalya gibi Avrupa ülkelerine ihraç edildiğinden dolayı ekonomik öneme sahip olup Kuzey Ege'de avcılığı yaygın olarak olta, uzatma ağı ve girgır ağlarıyla yapılmaktadır (Cengiz ve ark., 2013).

Ağırlık-boy ilişkisi balıkçılık yönetiminde sıklıkla kullanılan bir parametre olduğundan dolayı (Erzini, 1994), dünyanın değişik yerlerinde balık türlerinin bu ilişkisine değinen yayınların sayısında bir artış vardır (Froese ve ark., 2011). Ağırlı-boy ilişkisi (a) farklı habitatlardan ve/veya bölgelerden yakalanan balık türlerinin yaşam döngülerini ve morfolojilerini kıyaslamaya (Gonçalves ve ark., 1997; Moutopoulos ve Stergiou, 2002), (b) balık türlerinin büyümesindeki mevsimsel değişiklikleri ve kondisyon indekslerini izlemeye (Safran, 1992; Richter ve ark., 2000), (c) bir balık populasyonunun biyokütlesini hesaplamaya (Petrakis ve Stergiou, 1995; Dulčić ve Kraljević, 1996) olanak sağlamaktadır. Bu ilişkiler çalışma bölgesindeki çevresel şartlara ve örnekleme zamanına bağlı olarak değişebileceğinden dolayı (Torres ve ark., 2012) ağırlık-boy ilişkisine yönelik çalışmalar balık populasyonları için düzenli aralıklarla güncellenmelidir (İşmen ve ark., 2007; Özekinci ve ark., 2009).

Balıkların üreme zamanı balıkçılık yönetiminin ana konularından biri olup ilk üreme boyu, yumurta verimliliği gibi bilgilerin ortaya çıkarılması da mevcut 
balık stokları hakkında bilgi edinilmesi açısında önem taşımaktadır (Cengiz ve ark., 2015).

Ege Denizi'nde kupes balığının üremesi ile ilgili çalışmalar Gelibolu Yarımadası (Cengiz ve ark., 2014), Edremit Körfezi (Bilge, 2008; Çoktuğ, 2015), İzmir Körfezi (Bilge, 2008) ve Girit Adası'nda (Kallianiotis, 1992) gerçekleştirilmiş olmasına rağmen, Saros Körfezi’nde türün üreme zamanın belirlenmesine yönelik herhangi bir çalışma bulunmamaktadır. $\mathrm{Bu}$ çalışma bölgede kupes balığının ağırlık-boy ilişkisini güncellemekle beraber üreme zamanı ile ilgili ilk bilgileri içermektedir.

\section{MATERYAL ve YÖNTEM}

Ege Denizi'nin kuzeyinde yer alan Saros Körfezi (Şekil 1), güneyde Gelibolu Yarımadası ile kuzeyde Trakya kıyıları arasında bulunan ve yaklaşık olarak $60 \mathrm{~km}$ kadar içeri sokulan üçgen şeklinde bir körfezdir (Tokat ve Sayın, 2007). Körfez 2000 yllından beri trol avcılığına kapalıdır (Cengiz ve ark., 2011). Balık örnekleri bölgede Ocak 2014 - Aralık 2015 döneminde ticari balıkçılar yardımıyla 0-30 m arası derinliklerde uzatma ağları ile yakalanmıştır.

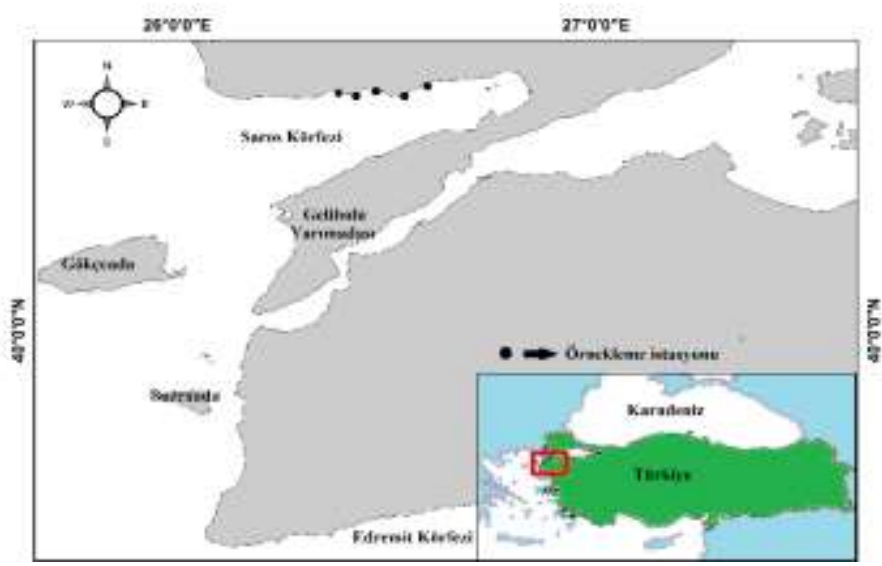

Şekil 1. Saros Körfezi ve örnekleme istasyonları

Örnekler, laboratuvara getirilene kadar buz kutularında korunmuştur. Balıkların boy ölçümleri için $\pm 1 \mathrm{~mm}$ hassasiyetli ölçüm tahtası kullanılmıştır. Vücut ağırlıklarının tartımı için $\pm 0.01 \mathrm{~g}$, gonad ağırlıklarının tartımı için ise $\pm 0.0001 \mathrm{~g}$ hassasiyete sahip terazi kullanılmıştır. Balıkların cinsiyeti çıplak gözle belirlenmiştir. Dişi ve erkek bireylerin sayıları arasındaki ilişkinin farklılığı Khi-kare $\left(x^{2}\right)$ testi ile yapilırken cinsiyetler arasindaki ortalama boy ve ağırlık arasındaki farkın bulunması Student's t testi yardımıyla saptanmıştır.

Türün ağırlık-boy ilişkisi Ricker (1975) tarafından önerilen $W=a L^{b}$ denklemi kullanılmak suretiyle dişi ve erkek bireyler için hesaplanmıştır. Bu denklemde $W$, gram cinsinden balığın toplam ağırlığ $;$; toplam boy $(\mathrm{cm}) ; a$ ve $b$ büyümeyi ifade eden sabitlerdir. Ĕger $b$ değeri 3’ten büyük ise tür pozitif allometrik büyüme, 3'den küçük ise negatif allometrik büyüme, 3'e eşit ise izometrik büyüme göstermektedir (Bagenel ve Tesch, 1978). $a$ ve $b$ parametrelerinin sonuçlarına t-testi uygulamak suretiyle her cinsiyetin $b$ değerinin izometrik büyümeden $(b=3)$ farklı olup olmadığı ve farklı ise büyümenin pozitif veya negatif olduğuna karar verilmiştir (Avşar, 2005).

Üreme dönemini tespit etmek amacıyla dişi ve erkek bireylerden alınan gonadların aylık ağırlık değişimleri dikkate alınmış ve Avşar (2005)'ın önerdiği eşitlikten faydalanılmıştır:

GSI (Gonadosomatik indeks $)=($ Gonad Ağırlığı / Vücut ağırlığı - Gonad Ağırlığı) $\times 100$

\section{BULGULAR}

İki yıllık çalışma sonunda örneklenen 963 bireyin 374 (\% 39.9) adedinin dişi, 564 (\% 60.1 adedinin erkek olduğu tespit edilmiştir. Dişi: erkek oranı 1:1.55 olup dişi ve erkek bireylerin sayıları arasındaki fark önemli bulunmuştur $\left(x^{2} ; \mathrm{P}<0.05\right)$. Dişi bireylerin boy ölçümü değerleri minimum $13.4 \mathrm{~cm}$. maksimum $27.6 \mathrm{~cm}$; ağırlıkları ise minimum 24.13 g. maksimum $259.63 \mathrm{gr}$ arasında değişim göstermiştir. Ortalama boy $19.8 \pm$ $2.98 \mathrm{~cm}$., ortalama ağırlık ise $97.43 \pm 42.39 \mathrm{gr}$ olarak belirlenmiştir. Erkek bireylerin boy ölçümü değerleri minimum $13.7 \mathrm{~cm}$. maksimum $25.6 \mathrm{~cm}$; ağırlıkları ise minimum $25.93 \mathrm{gr}$ ve maksimum $204.00 \mathrm{~g}$ arasındadır. Ortalama boy $20.5 \pm 2.46 \mathrm{~cm}$., ortalama ağırlık ise $105.93 \pm 35.16$ gr olarak saptanmıştır. Student's t testi dişi ve erkek bireylerin ortalama boyları ve ortalama ağırlıkları arasında, istatistiksel açıdan, fark olmadığını göstermiştir $(\mathrm{P}>0.05)$. Örneklenen dişi ve erkek bireylere ait boy dağılımı Şekil 2'de gösterilmektedir.

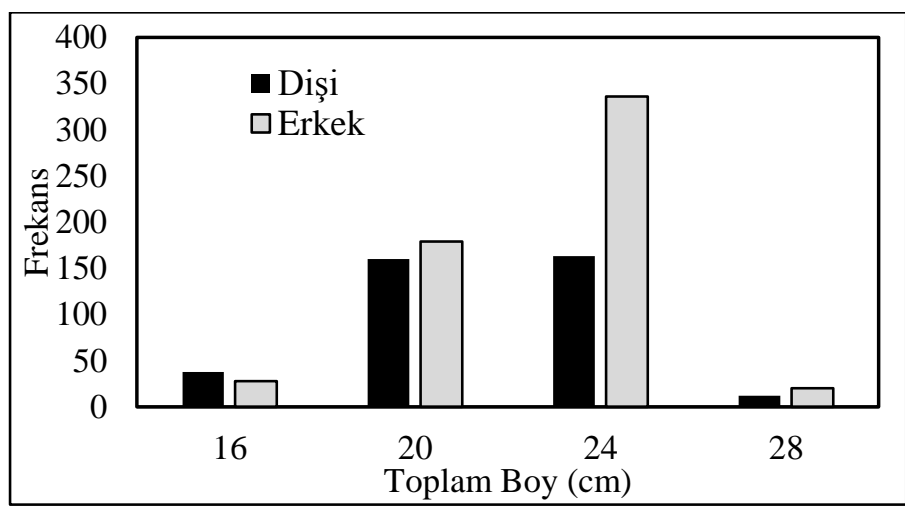

Şekil 2. Dişi ve erkek bireylerin boy dağılımı

Dişi bireyler için ağırlık-boy ilişkisi $\mathrm{W}=0.0085 \mathrm{TL}^{3.11}$, erkek bireyler için $\mathrm{W}=0.0095 \mathrm{TL}^{3.07}$ olarak ayrı ayrı hesaplanmıştır. T-testi sonucu dişi bireylerin pozitif allometrik büyüme, erkek bireylerin izometrik büyüme gösterdikleri saptanmıştır. Dişi ve erkek bireyle ait ağırlık-boy ilişkisi Şekil 3'de gösterilmektedir. 


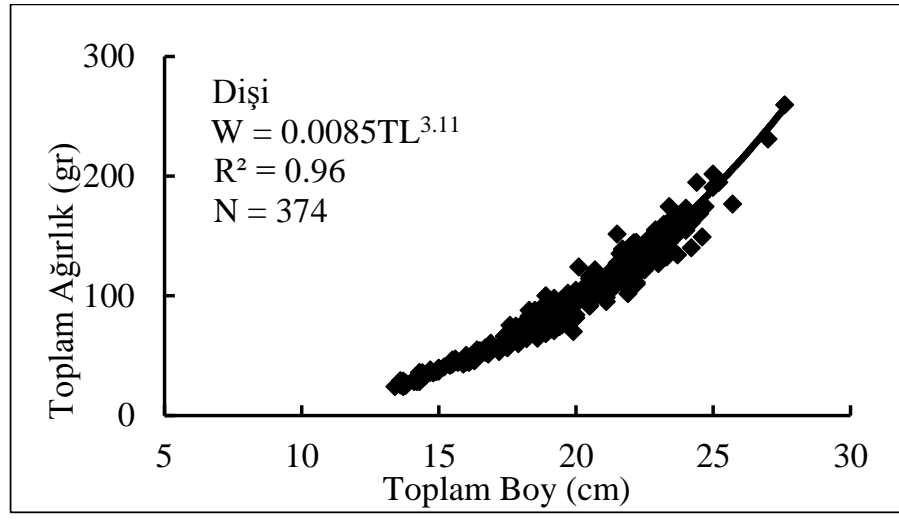

Şekil 3: Dişi ve erkek bireylere ait ağırlık-boy ilişkileri

Kupes balığının aylara göre GSI değerleri dişi bireyler için 0.36 ile 9.82 arasında, erkek bireyler için ise 0.34 ile 8.83 arasında değişim sergilemektedir. Bu değerlerin her iki yıl için Ocak aylarında artmaya

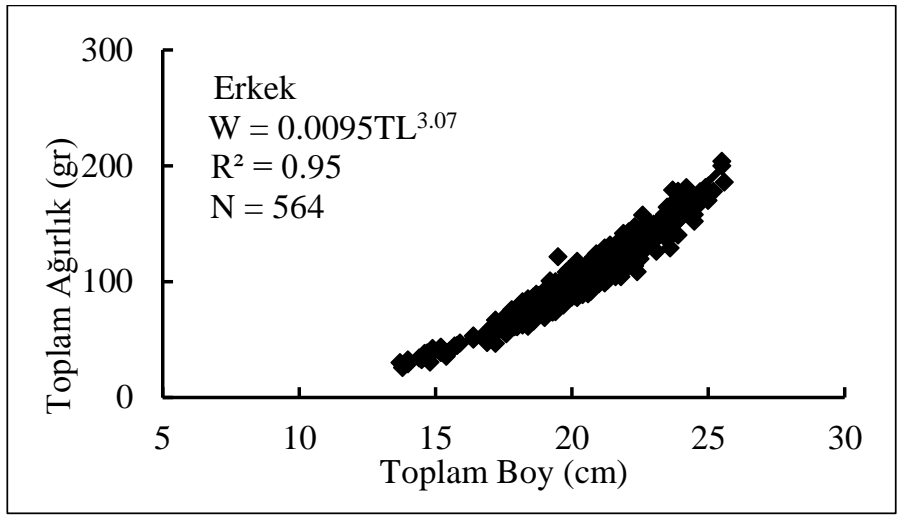

başladığı Mart aylarında en yüksek, Temmuz ve Eylül aylarında en düşük olduğu tespit edilmiştir. Üreme zamanının Mart ayından başlayarak Mayıs ayına kadar olduğu görülmüştür (Şekil 4).

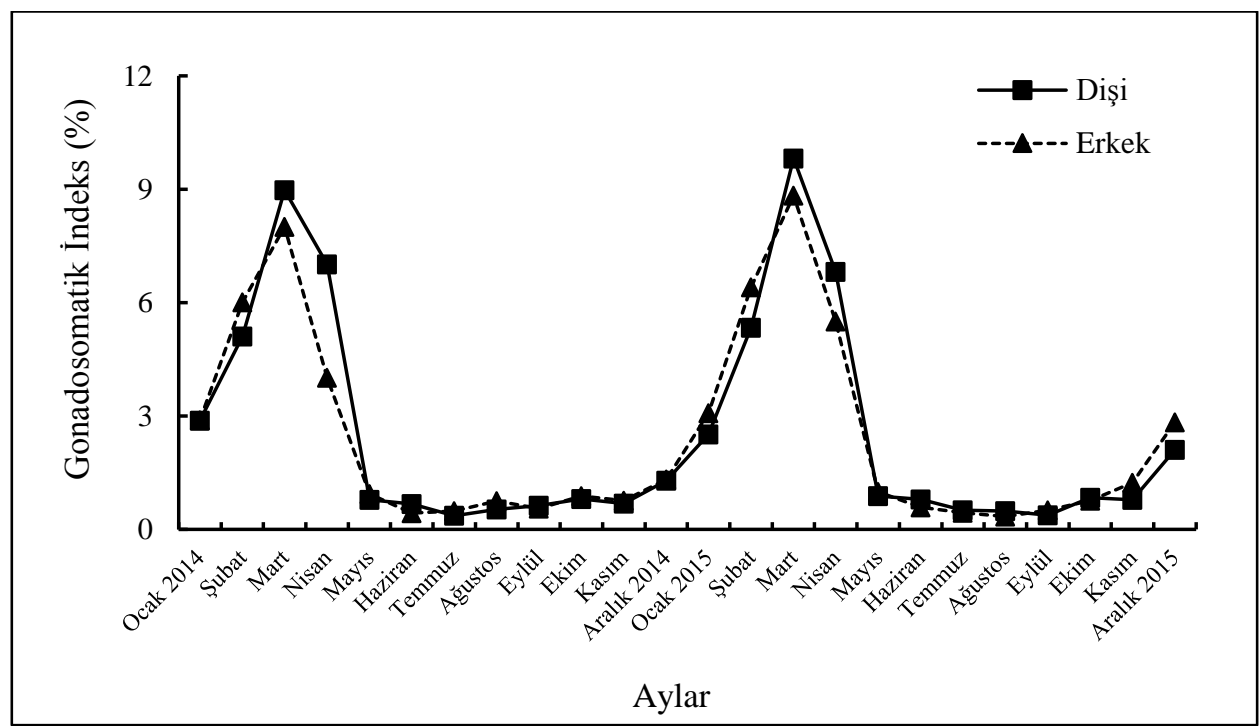

Şekil 4. Dişi ve erkek bireylere ait aylık GSI değerleri

\section{TARTIŞMA ve SONUÇ}

Birçok araştırmacı (Özaydın ve ark., 2000; İşmen ve ark., 2007; İlkyaz ve ark., 2010; Kapiris ve Klaoudaos, 2011; Cengiz, 2013) farklı balık türleri üzerinde yaptıkları çalışmalarda boy ve ağırlık aralıklarını etkileyen faktörlerin örnekleme yöntemi ve zamanı, bölgeler arasında görülen sicaklık varyasyonları, beslenme faaliyetleri, örneklemede kullanılan farklı av araçları ve bu av araçlarının seçicilik özellikleri olduğunu belirtmişlerdir. Benzer şekilde, ağırlık-boy ilişkisi balıkların cinsiyetine, gonad gelişimine, çevresel faktörlerdeki yıllık değişimlere, mevsimsel farklılıklara ve türlerin korunmasına yönelik alınan önlemlere (Dulčić ve Kraljević, 1996; Wootton, 1998; Froese, 2006; Verdiell-Cubedo ve ark., 2006), yakalanan birey sayısına ve bireylerin boy ve ağırlık aralıklarına (Moutopoulos ve Stergiou, 2002) bağlıdır.
Çizelge 1'e bakıldığında bu çalışma ile önceki çalışmalar arasında boy ve ağırlık aralıklarında ve ağırlık-boy ilişkilerinde görülün farklılıklar yukarıda bahsedilen bir veya birden fazla etmenle açıklanabilir.

Balıkların üreme zamanı bulundukları ortamın çevresel ve ekolojik özellikleri ile yakın bir ilişkiye sahiptir (İlkyaz ve ark., 2010). Çizelge 2 ise farklı bölgelerden yakalanan kupes balıklarının üreme zamanını göstermektedir.

Sonuç olarak, burada sunulan veriler Akdeniz Havzasının farklı bölgelerinde gerçekleştirilecek olan sonraki balıkçılık çalışmalarında benzer parametreleri karşılaştırmak için kullanılabilir. $\mathrm{Bu}$ çalışmanın sonuçları, kupes balığının stok durumunu belirlemek için gerekli bilimsel desteği sağlamak suretiyle türün korunmasına ve yönetimine yardımcı olacaktır. 
Çizelge 1. Farklı bölgelerden yakalanan kupes balığının boy aralığının ve ağırlık-boy ilişkisinin karşılaştırılması

\begin{tabular}{|c|c|c|c|c|c|c|c|}
\hline Yazar(lar) & Bölge & Cinsiyet & $\mathbf{N}$ & $\begin{array}{l}\text { Boy } \\
\text { Aralığ }(\mathrm{cm})\end{array}$ & $\begin{array}{l}\text { Ağırlık } \\
\text { aralığı (g) }\end{array}$ & a & b \\
\hline Meralla ve ark.(1997) & Balear Adaları & $\Sigma$ & 228 & $12.4-26.6$ & - & 0.0082 & 3.00 \\
\hline Abdallah (2002) & Misir & $\Sigma$ & 284 & $3.7-14.6$ & - & 0.0070 & 3.13 \\
\hline Borges ve ark. (2003) & Algarve & $\Sigma$ & 505 & $9.8-26.9$ & $8.0-204.8$ & 0.0120 & 2.89 \\
\hline Mendes ve ark. (2004) & Portekiz & $\Sigma$ & 277 & $16.6-34.6$ & $40.0-520.0$ & 0.0074 & 3.08 \\
\hline Cicek ve ark. (2006) & $\begin{array}{l}\text { Babadillimani } \\
\text { Limanı }\end{array}$ & $\Sigma$ & 391 & $7.5-21.4$ & $3.52-99.98$ & 0.0080 & 3.04 \\
\hline Karakulak ve ark. (2006) & Gökceada & $\begin{array}{l}0 \\
+ \\
0\end{array}$ & $\begin{array}{l}232 \\
213\end{array}$ & $\begin{array}{l}15.4-32.1 \\
15.3-27.8\end{array}$ & - & $\begin{array}{l}0.0032 \\
0.0074\end{array}$ & $\begin{array}{l}3.39 \\
3.11\end{array}$ \\
\hline Ismen ve ark. (2007) & Saros Körfezi & $\Sigma$ & 189 & $10.5-22.0$ & $11.00-91.00$ & 0.0045 & 3.24 \\
\hline Kara ve Bayhan (2008) & Izmir Körfezi & $\begin{array}{l}+9 \\
+9 \\
\end{array}$ & $\begin{array}{l}640 \\
516\end{array}$ & $\begin{array}{l}11.3-27.6 \\
13.6-27.0\end{array}$ & $\begin{array}{l}12.10-261.76 \\
17.70-281.67\end{array}$ & $\begin{array}{l}0.0044 \\
0.0021\end{array}$ & $\begin{array}{l}3.27 \\
3.52 \\
\end{array}$ \\
\hline $\begin{array}{lll}\begin{array}{l}\text { Moutopoulos } \\
(2013)\end{array} & \text { ve } & \text { ark. } \\
\end{array}$ & $\begin{array}{l}\text { Korinthiakos } \\
\text { Körfezi }\end{array}$ & $\Sigma$ & 724 & $11.7-34.0$ & - & 0.0070 & 3.09 \\
\hline Bu çalışma & Saros Körfezi & $\begin{array}{l}\text { o } \\
\text { o }\end{array}$ & $\begin{array}{l}374 \\
564\end{array}$ & $\begin{array}{l}13.4-27.6 \\
13.7-25.6\end{array}$ & $\begin{array}{l}24.13-259.63 \\
25.93-204.00\end{array}$ & $\begin{array}{l}0.0085 \\
0.0095\end{array}$ & $\begin{array}{l}3.11 \\
3.07\end{array}$ \\
\hline
\end{tabular}

q $=$ Dişi birey, $\hat{\jmath}=$ Erkek birey, $\Sigma=$ Toplam birey

Çizelge 2. Farklı bölgelerden yakalanan kupes balığının üreme zamanlarının karşılaştırılması

\begin{tabular}{lll}
\hline Yazar(lar) & Bölge & Üreme Zamanı \\
\hline Girardin (1981) & Lion Körfezi & Mart - Haziran \\
\hline Anato ve Ktari (1983) & Tunus & Mart - Haziran \\
\hline Chali-Cabane (1988*) & Nijerya & Mart - Haziran \\
\hline Alegría-Hernández (1990) & Dalmatia & Mart - Mayıs \\
\hline Campillo (1992) & Lion Körfezi & Mart - Haziran \\
\hline Kallianiotis (1992) & Girit & Ocak - Nisan \\
\hline Lamrini (1998) & Cebelitarık Boğazı & Nisan - Temmuz \\
\hline El-Agamy ve ark. (2004) & Misır & Ocak - Mayıs \\
\hline Monterio ve ark. (2006) & Algarve & Şubat - Mayıs \\
\hline Bilge (2008) & İzmir Körfezi & Mart - Haziran \\
\hline Bottari ve ark. (2014) & Edremit Bay & Nisan - Temmuz \\
\hline Cengiz ve ark. (2014) & Güney Tyrrhenian Denizi & Şubat - Nisan \\
\hline Çoktuğ (2015) & Gelibolu Yarımadası & Mart - Mayıs \\
\hline Bu çalışma & Edremit Körfezi & Ocak - Mayıs \\
\hline
\end{tabular}

* Relini ve ark. (1999)

\section{TEŞEKKÜR}

Yazar yardımlarından dolayı balıkçı Engin Tunç’a ve öğretim görevlisi Semih Kale'ye teşekkür ediyor.

\section{KAYNAKLAR}

Abdallah M 2002. Length-Weight Relationships of Fishes Caught by Trawl off Alexandria, Egypt. Naga ICLARM, 25: 19-20.

Alegría-Hernández V 1990. Some Aspects of the Reproductive Biology of Bogue (Boops boops L., Pisces, Sparidae) from the Mid-Adriatic Channels. Acta Adriatica, 31: 301-313.
Anato CB, Ktari MH 1983. Reproduction de Boops boops (Linné, 1758) et de Sarpa salpa (Linné, 1758), Poissons, Téléostéens, Sparidés du Golfe de Tunis. Bull. Inst. Natn. Scient. Tech. Ocêanog. Pêche Salammbô, 10: 49-53.

Avşar D 2005. Balıkçılık Biyolojisi ve Populasyon Dinamiği. Nobel Kitabevi, Adana.

Bagenal TB, Tesch FW 1978. Age and growth. In: Methods for Assessment of Fish Production in Fresh Waters, (T.B. Bagenal ed), 3rd edition. IBP Handbook No. 3, Blackwell Science Publications, Oxford: 101-136. 
Bauchot ML, Hureau JC 1986. Sparidae, vol. 2. p. 883907. In: Fishes of the North- Eastern Atlantic and the Mediterranean edited by P. J. P. Whitehead, M.L Bauchot, J.C Hureau, J. Nilson and E. Tortonese, UNESCO. Paris.

Bilge G. 2008. Ege Denizi'nde Kupez Balığı (Boops boops Linnaeus, 1758)'nın Biyo-ekolojik Özellikleri. Ege Üniversitesi Fen Bil. Ens., Su Ürünleri Temel Bilimler ABD, Doktora Tezi, $131 \mathrm{~s}$.

Borges TC, Olim S, Erzini K 2003. Weight-length relationships for fish species discarded in commercial fisheries of the Algarve (southern Portugal). Journal of Applied Ichthyology, 19: 394396.

Campillo A 1992. Les Pêcheries Françaises de Méditerranée: Synthèse des Connaissances. Institut Français de Recherche pour l'Exploitation de la Mer, France, 206 pp.

Cengiz Ö, İşmen A, Özekinci U, Öztekin A 2011. Saroz Körfezi (Kuzey Ege Denizi) Balık Faunası Üzerine Bir Araştırma. Afyon Kocatepe Üniversitesi Fen Bilimleri Dergisi, 11: 31-37.

Cengiz Ö 2013. Length-Weight Relationships of 22 Fish Species from the Gallipoli Peninsula and Dardanelles (northeastern Mediterranean, Turkey). Turkish Journal of Zoology, 37: 419-422.

Cengiz Ö, Ayaz A, Öztekin A, Kumova C 2013. Gelibolu Yarımadası'nda (Kuzey Ege Denizi, Türkiye) Kupes Balığı (Boops boops Linnaeus, 1758) Avcılığında Kullanılan Multifilament Galsama Ağı Seçiciliğinin Boy-Çevre İlişkisi İle Belirlenmesi. Menba Su Ürünleri Fakültesi Dergisi, 1: 28-32.

Cengiz Ö, Ayaz A, Özekinci U, Öztekin A, Aslan A 2014. Length-Weight Relationship and Reproduction of Bogue (Boops boops Linnaeus, 1758) from Gallipoli Peninsula (Northern Aegean Sea, Turkey). 5th International Symposium on Sustainable Development, 15-18 May 2014, Sarajevo, Bosnia Herzegovina.

Cengiz Ö, Özekinci U, İşmen A, Öztekin A 2015. Saros Körfezi (Kuzey Ege Denizi, Türkiye) 'nden Avlanan Benekli Pisi Balığının (Lepidorhombus boscii Risso, 1810) Bazı Üreme Özellikleri. Tarım Bilimleri Dergisi, 21(2): 270-278.

Cicek E, Avsar D, Yeldan H, Ozutok M 2006. LengthWeight Relationships for 31 Teleost Fishes Caught by Bottom Trawl Net in the Babadillimani Bight (northeastern Mediterranean). Journal of Applied Ichthyology, 22: 290-292.

Çoktuğ B 2015. Ege Denizi Edremit Körfezi'nde Yaşayan Kupez Balığı (Boops boops linnaeus, 1758) 'nın Bazı Biyolojik Özellikleri. Balıkesir Üniversitesi Fen Bil. Ens., Biyoloji ABD, Yüksek Lisans Tezi, $54 \mathrm{~s}$.

Dulčić J, Kraljević M 1996. Weight-Length Relationships for 40 fish species in the Eastern Adriatic (Croatian waters). Fisheries Research, 28: 243-251.
El-Aagamy A, Zaki MI, Awad GS, Negm RK 2004. Reproductive Biology of Boops boops (Family Sparidae) in the Mediterranean Environment. Egyptian Journal of Aquatic Research, 30: 241-254.

Erzini K 1994. An Empirical Study of Variability in Length at Age of Marine Fishes. Journal of Applied Ichthyology, 10: 17-41

Fricke R, Bilecenoğlu M, Sarı HM 2007. Annotated Checklist of Fish and Lamprey Species of Turkey, Including a Red List of Threatened and Declining Species. Stuttgarter Beitrage zur Naturkunde Serie A (Biologie), 706: 1-169.

Froese R 2006. Cubelaw, Condition Factor and WeightLength Relationships: History, Meta-analysis and Recommendations. Journal of Applied Ichthyology, 22: 241-253.

Froese R, Tsikliras AC, Stergiou KI 2011. Editorial Note on Weight-Length Relations of Fishes. Acta Ichthyologica et Piscatoria, 41: 261-263.

Girardin M 1981. Pagellus erythrinus (L. 1758) et Boops boops (L.,1758) (Pisces, Sparidae) du Golf edu Lion. Thèse d'Ecologie générale et appliquée. Académie de Montpellier 2. $295 \mathrm{pp}$.

Gonçalves JMS, Bentes L, Lino PG, Ribeiro J, Canário AVM, Erzini K 1997. Weight-Length Relationships for Selected Fish Species of the Small-Scale Demersal Fisheries of the South and Southwest Coast of Portugal. Fisheries Research, 30: 253-256.

İlkyaz AT, Metin G, Soykan O, Kınacigil HT 2010. Age, Growth and Sexual Development of solenette, Buglossidium luteum (Risso, 1810), in the Central Aegean Sea. Journal of Applied Ichthyology, 26: 436-440.

İşmen A, Özen O, Altınağaç U, Özekinci U, Ayaz A 2007. Weight-Length Relationships of 63 Fish Species in Saros Bay, Turkey. Journal of Applied Ichthyology, 23: 707-708.

Kallianiotis AA 1992. Biology and Population Structure of Bogue [Boops boops (L.)] Populations in the Marine Area of Crete. Doctorate dissertation, University of Crete, Greece.

Kara A, Bayhan B 2008. Length-Weight and LengthLength Relationships of the Bogue Boops boops (Linnaeus, 1758) in Izmir Bay (Aegean Sea of Turkey). Belgian Journal of Zoology, 138: 154-157.

Kapiris K, Klaoudatos D 2011. Length-Weight Relationships for 21 Fish Species Caught in the Argolikos Gulf (central Aegean Sea, eastern Mediterranean). Turkish Journal of Zoology, 35: 717-723.

Karakulak FS, Erk H, Bilgin B 2006. Length-Weight Relationships for 47 Coastal Fish Species from the Northern Aegean Sea, Turkey. Journal of Applied Ichthyology, 22: 274-278.

Lamrini A 1998. Sexualité de la Bogue (Boops boops, Linnaeus, 1758) au sud du Détroit de Gibraltar. Actes de l'Institut Agronomique et Vétérinaire (Maroc), 18: 5-14. 
Mendes B, Fonseca P, Campos A 2004. Weight-Length Relationships for 46 Fish Species of the Portuguese west coast. Journal of Applied Ichthyology, 20: 355361.

Merella P, Quetglas A, Alemany F, Carbonell A 1997. Length-Weight Relationship of Fishes and Cephalopods from the Balearic Islands (western Mediterranean). Naga ICLARM, 20: 66-68.

Monteiro P, Bentes L, Coelho R, Correia C, Gonçalves JMS, Lino PG, Ribeiro J, Erzini K 2006. Age and Growth, Mortality, Reproduction and Relative Yield Per Recruit of the Bogue, Boops boops Linné, 1758 (Sparidae), from the Algarve (south of Portugal) Longline Fishery. Journal of Applied Ichthyology, 22: 345-352.

Moutopoulos DK, Stergiou KI 2002. Length-Weight and Length-Length Relationships of Fish Species from the Aegean Sea (Greece). Journal of Applied Ichthyology, 18: 200-203.

Moutopoulos DK, Ramfos A, Mouka A, Katselis G 2013. Length-Weight Relations of 34 Fish Species Caught by Small-Scale Fishery in Korinthiakos Gulf (Central Greece). Acta Ichthyologica et Piscatoria, 43: 57-64.

Özaydın O, Bilecenoğlu M, Kaya M 2000. Age and Growth of the Curled Picarel Centracanthus cirrus Rafinesque, 1810 (Osteichthyes: Centracanthidae) in Northern Cyprus, Eastern Mediterranean Sea. Acta Adriatica 41: 35-42.

Özekinci U, Cengiz Ö, İşmen A, Altınağaç U, Ayaz A 2009. Length-Weight Relationships of Thirteen Flatfishes (Pisces: Pleuronectiformes) from Saroz Bay (North Aegean Sea, Turkey). Journal Animal and Veterinary Advences, 8: 1800-1801.

Petrakis D, Stergiou KI 1995. Weight-Length Relationships for 33 Fish Species in Greek waters. Fisheries Research, 21: 465-469.

Relini G, Bertrand J, Zamboni A 1999. Synthesis of the Knowledge on Bottom Fishery Resources in Central Mediterranean (Italy and Corsica). Biologia Marina Mediterranea, 6 (suppl. 1): 382-386.

Richter H, Lückstädt C, Focken U, Becker K 2000. An Improved Procedure to Assess Fish Condition on the Basis of Length-Weight Relationships. Archive of Fishery and Marine Research, 48: 255-264.

Ricker WE 1975. Computation and Interpretation of Biological Statistics of Fish Populations. Journal of the Fisheries Research Board of Canada, 191: 1382.

Safran P 1992. Theoretical Analysis of the WeightLength Relationships in Fish Juveniles. Marine Biology, 112: 545-551.

Tokat E, Sayın E 2007. Water Masses Influencing the Hydrographic Properties of Saros Bay. Rapp Comm Int Mer Medit, 38: 205.

Torres MA, Ramos F, Sobrino I 2012. Length-Weight Relationships of 76 Fish Species from the Gulf of Cadiz (SW Spain). Fisheries Research, 127-128: 171-175.

Verdiell-Cubedo D, Oliva-Paterna FJ, Torralva M 2006. Length-Weight Relationships for 22 Fish Species of the Mar Menor Coastal Lagoon (western Mediterranean Sea). Journal of Applied Ichthyology, 22: 293-294.

Wootton RJ 1998. Ecology of Teleost Fishes. 2nd Edition, Kluwer Academic, London. 